\title{
Growing Teratoma Syndrome
}

\author{
1Jyoti R Chandran, ${ }^{2}$ Sumangala Devi D
}

\begin{abstract}
Growing teratoma syndrome (GTS) is seen in young women following surgery for immature teratoma of the ovary. It needs management with adjuvant chemotherapy following debulking procedures for residual disease.

Keywords: Growing teratoma syndrome, Immature teratoma, Malignant germ cell tumor.
\end{abstract}

How to cite this article: Chandran JR, Devi SD. Growing Teratoma Syndrome. World J Anemia 2018;2(2):68-70.

\section{Source of support: Nil}

Conflict of interest: None

\section{INTRODUCTION}

Growing teratoma syndrome (GTS) is a rare metastatic complication of malignant germ cell tumor. It was first described in nonseminomatous germ cell tumor (NSGCT) of testes. While the incidence of NSGCT of the testes treated with chemotherapy is between $1.9 \%$ and $7.5 \%$, it is very rarely seen in the ovary. We are reporting this case for its rarity.

\section{CASE REPORT}

A 22-year-old Mrs S, G2P1L1, LCB 5 years, with LMP on October 6, 2014, and expected date of confinement on July 13, 2015, at 38 weeks of gestation admitted for safe confinement. Her antenatal period was uneventful, and she was carrying a healthy fetus.

\section{Past History}

First pregnancy: At 9 weeks of gestation her ultrasonogram showed a live intrauterine pregnancy with corresponding growth and a heteroechoic right ovarian cyst of size $54 \times 35 \mathrm{~mm}$ with cystic and solid components (? dermoid).

\footnotetext{
1,2 Professor

${ }^{1}$ Department of Obstetrics and Gynaecology, Government Medical College, Calicut, Kerala, India

${ }^{2}$ Department of Obstetrics and Gynaecology, Government Medical College, Kozhikode, Kerala, India

Corresponding Author: Jyoti R Chandran, Professor, Department of Obstetrics and Gynaecology, Government Medical College, Calicut, Kerala, India, e-mail: drjyotichandran@ gmail.com
}

A repeat USG at 16 weeks showed an increase in the size of the cyst to $94 \times 104 \mathrm{~mm}$. Hence on 20/09/2010, a laparotomy with right ovariotomy was done. Left ovary normal.

- Histopathology report: Macroscopy-Brownish nodular mass measuring $12 \times 13 \times 6 \mathrm{~cm}$ capsule appears ruptured, cut section shows solid and cystic spaces, solid areas whitish glistening and cystic spaces filled with mucinous material, cartilage, hair, and fat.

Microscopy shows ovarian cyst lined by squamous epithelium. The section from solid areas shows glial tissue, choroid plexus, lobules of fat, cartilage, bony tissue, and skin appendages.

\section{Diagnosis: Mature Teratoma (Benign)}

She had normal term delivery one week before the expected date of confinement $/ 3 \mathrm{~kg}$ male baby in February 2011. No other antepartum/intrapartum or postpartum complications.

Two months later, she had complaints of mass in the abdomen for which she consulted a doctor, and ultrasonogram was done which showed a multicystic heteroechoic mass measuring $18 \times 10.4 \mathrm{~cm}$ seen in the pelvis extending to the right side of the abdomen. Another mass of size 18.1 $\times 8.4 \mathrm{~cm}$ seen in the supraumbilical region.

\section{Contrast-enhanced Computed Tomography}

Well defined heterogenous solid and cystic mass measuring $16 \times 13 \mathrm{~cm}$ showing scattered areas of fat, calcification, and soft tissue component is seen in the pelvis (midline and the right side). Lesion shows minimal post contrast enhancement suggestive of immature teratoma. The lesion is seen to displace the bowel loop to the left side. Superiorly it is reaching the level of the umbilicus. Stranding of fat seen adjacent to the lesion infiltration? Another lesion measuring $16 \times 10 \mathrm{~cm}$ with similar appearance seen in the right suprarenal region. The lesion is seen abutting the posterior surface of the right lobe of the liver. The fat plane between the lesion and liver is not clearly defined. Heterogeneous attenuation lesion is also seen in the right perihepatic region and subdiaphragmatic location suggestive of immature teratoma with the capsular breach and peritoneal extension. Ascites are seen. Right adrenal not visualized separately. Both ovaries not well visualized. The remote possibility of a capsular breach and granulomatous peritonitis also need to be considered. 
- Blood investigations: WNL, tumor markers- $\beta$ hCG: $<0.1$ $\mathrm{IU} / \mathrm{mL}$, AFP: $280.3 \mathrm{ng} / \mathrm{mL}$

Laparotomy was done on 02/05/2011, and intraoperative findings were uterus shows small granules, right ovary not visible, left ovary normal, a large cystic mass with solid components about $20 \times 18 \mathrm{~cm}$ arising from the omentum. Ascites was present, and bowel also showed granular deposits, a large mass $18 \times 15 \mathrm{~cm}$ in a subhepatic area with yellowish fluid and solid content, mass removed from the omentum and mass under the liver debulked (whole mass could not be removed) and sent for HPE.

- Histopathological examination: Tumor mass from omentum- Immature teratoma grade 2, tumor mass under liver-peritoneal gliomatosis, omentum-teratomatous nodule with peritoneal gliomatosis and ascitic fluid cytology-occasional clusters of atypical cells and mononuclear cells.

Postoperative adjuvant chemotherapy with bleomycin, etoposide and paclitaxel regimen five cycles completed. The patient was on regular follow-up. Repeat USG taken 2 months postoperatively showed an ill-defined mixed echogenic complex solid and cystic mass lesion in right suprarenal/subhepatic area of size $12 \times 8 \mathrm{~cm}$. The lesion is compressing/intending the under the surface of the liver and extending perihepatically. Omental deposits are likely.

She underwent repeat laparotomy done on 02/09/2011 intraoperative findings: Large retroperitoneal tumor $13 \times 10 \mathrm{~cm}$, solid and cystic, predominantly solid. Densely adherent to the diaphragm, under the surface of the liver. No ascitis. No visceral disease. Tumor excised in toto enbloc with part of the diaphragm.

Patient developed hemoperitoneum in the immediate postoperative reexploration was done. A $1.5 \mathrm{~L}$ of blood. Bleeding from the undersurface of a liver parenchyma; no major bleed; perihepatic packing done.

Reexploration was done on 05/09/2011-bleeding from a right hepatic vein near the IVC-right hepatectomy done, hemostasis maintained.

Final diagnosis-growing teratoma syndrome (retroperitoneum).

The patient was on regular follow-up. No further abdominal masses detected. She conceived for the second time in October 2014 and she delivered normally on July 12, 2015, without any complications.

\section{DISCUSSION}

Growing teratoma syndrome (GTS), is defined as an enlarging mature teratoma that arises during or following chemotherapy for a malignant germ cell tumor. ${ }^{1}$ Two possible explanations for the occurrence include selective elimination of the malignant cells by chemotherapeutic agents or differentiation of malignant cells into mature teratoma components following exposure to chemotherapeutic agents. Other explanation for the appearance of GTS may be as a result of micrometastases of the remaining immature teratoma cells within the peritoneal cavity. This may be as a result of intra-abdominal dissemination despite intact capsule which may occur spontaneously preoperatively.

The presenting symptoms may be abdominal distension or abdominal discomfort as in our case, and the initial histopathology may be an immature teratoma. As the patients are young, they may undergo unilateral salpingo-ovariotomy due to fertility concerns. The development of GTS had been reported as early as 3 months and in some cases, delayed until 8 years. Our patient developed GTS after 7 months. Monitoring of response to chemotherapy is by serum tumor markers till low or normal levels. ${ }^{2-11}$ However, despite normalization of serum tumor markers during chemotherapy, the metastatic tumor grows and is usually identified on radiological imaging or ultrasonography, and complete surgical excision is the treatment of choice with retroperitoneal para-aortic and pelvic lymph node dissection. Malignant transformation has been reported in $3 \%$ of the cases.

The overall prognosis for GTS is good with few reported deaths. The 5 -year survival rate is $89 \%$ for patients who have undergone surgery following GTS. However, close follow-up is essential as GTS has developed 10 years later on follow-up.

\section{CONCLUSION}

Our patient had two successful pregnancy outcome following GTS and is on follow-up.

\section{REFERENCES}

1. Logothetis CJ, Samuels ML, Trindade A, Johnson DE. The growing teratoma syndrome. Cancer. 1982 Oct 15;50(8):16291635.

2. Hsieh TY, Cheng YM, Chang FM, Chou CY. Growing teratoma syndrome: an Asian woman with immature teratoma of left ovary after chemotherapy. Taiwanese journal of obstetrics and gynecology. 2009 Jun 1;48(2):186-189.

3. Hariprasad R, Kumar L, Janga D, Kumar S, Vijayaraghavan M. Growing teratoma syndrome of ovary. International Journal of Clinical Oncology. 2008 Feb 1;13(1):83-87.

4. Nimkin K, Gupta P, McCauley R, Gilchrist BF, Lessin MS. The growing teratoma syndrome. Pediatric radiology. 2004 Mar 1;34(3):259-262.

5. Matsushita H, Arai K, Fukase M, Takayanagi T, Ikarashi H. Growing teratoma syndrome of the ovary after fertilitysparing surgery and successful pregnancy. Gynecologic and obstetric investigation. 2010;69(4):221-223. 
6. Rekha W, Amita M, Sudeep G, Shubhada K, Hemant T. Growing teratoma syndrome in germ cell tumour of the ovary: a case report. Australian and New Zealand journal of obstetrics and gynaecology. 2005 Apr 1;45(2):170-171.

7. Itani Y, Kawa M, Toyoda S, Yamagami K, Hiraoka K. Growing teratoma syndrome after chemotherapy for a mixed germ cell tumor of the ovary. Journal of obstetrics and gynaecology research. 2002 Jun 1;28(3):166-171.

8. Sengar AR, Kulkarni JN. Growing teratoma syndrome in a post laparoscopic excision of ovarian immature teratoma. Journal of gynecologic oncology. 2010 Jun 1;21(2): 129-131.
9. Tzortzatos G, Sioutas A, Schedvins K. Successful pregnancy after treatment for ovarian malignant teratoma with growing teratoma syndrome. Fertility and sterility. 2009 Mar 1;91(3):936-e1.

10. Tejura $\mathrm{H}, \mathrm{O}^{\prime}$ Leary A. Growing teratoma syndrome after chemotherapy for germ cell tumour of the ovary. Journal of obstetrics and gynaecology. 2005 Apr 1;25(3):296-297.

11. Andre F, Fizazi K, Culine S, Droz JP, Taupin P, Lhomme $\mathrm{C}$, Terrier-Lacombe MJ, et al. The growing teratoma syndrome: results of therapy and long-term follow-up of 33 patients. European Journal of Cancer. 2000 Jul 1;36(11): 1389-1394. 